\title{
Ethnic Minority Professionals' Experiences with Subtle Discrimination in the Workplace
}

$\underline{\text { Authors }}$

Koen Van Laer, K.U.Leuven, koen.vanlaer@econ.kuleuven.be

Maddy Janssens, Katholieke U. Leuven, maddy.janssens@econ.kuleuven.be 


\title{
Ethnic minority professionals' experiences with subtle discrimination in the workplace
}

\begin{abstract}
This qualitative study examines subtle discrimination in the workplace from the target's perspective and aims to explore the different forms subtle discrimination can take, and the reasons why minority individuals themselves experience specific incidents as discriminatory. Based on in-depth interviews with minority professionals of Turkish and Maghrebi descent in Flanders, we identified a large variety of different forms of subtle discrimination and four major reasons that explain their problematic nature. These reasons involve the feeling that the lower status of ethnic minorities is reinforced; feeling treated as a representative of an ethnic group; the feeling that specific differences are seen as problematic; and the feeling that the unequal status-quo is maintained. Linking subtle discrimination to power, we discuss how hierarchization and exotization of ascribed differences, the confrontation with the dominant Norm, and the maintenance of the current 'ethnic structures' are essential to understand experiences of subtle discrimination.
\end{abstract}

Keywords: Discrimination, ethnic minorities, power, diversity

\section{Introduction}

On 11 May 2006, an eighteen-year-old boy walked through the streets of Antwerp, one of the major cities in Belgium, with a hunting rifle. He wanted to kill as many people of foreign descent as possible and shot three people: a two-year-old Belgian girl and her pregnant Malian nanny were killed; a woman of Turkish descent was heavily wounded but survived the attack. Belgium and its politicians reacted in shock and tried to understand how the racist 
shooting could have happened. However, representatives of multicultural organizations (El Omari and Lahlali, 2006) asked politicians, and society at large, to not only worry about exceptional racist incidents but to also address subtle, everyday forms of racism and discrimination, which might be less visible, but nevertheless have dire consequences. In this paper, we try answer such calls and contribute to this debate by exploring subtle discrimination in the workplace

In line with the criticism raised by these Flemish multicultural organizations, organizational scholars have also argued that too little attention has been paid to subtle forms of discrimination entrenched in everyday workplace interactions. In doing so, the literature on workplace discrimination has "failed to adequately sample the range of discriminatory events experienced by stigmatized individuals on the job" (Deitch et al., 2003:1300). In line with calls for more attention for such subtle forms of discrimination in the workplace (e.g. Deitch et al., 2003; Dovidio and Hebl, 2001; Ogbonna and Harris, 2006), some studies have conceptualized the ambiguity of such forms of discrimination and provided evidence for its existence and its detrimental effects (Deitch, et al., 2003; Dipboye and Halverson, 2004). However, our knowledge remains limited about the reasons why individuals experience certain behaviors as forms of subtle discrimination.

In this study, we aim to increase our understanding of subtle discrimination in the workplace by exploring why ethnic minority professionals themselves experience particular encounters with majority colleagues as discriminatory. Based on previous definitions of discrimination as differential or unfair treatment of individuals because of a specific sociodemographic characteristic, resulting in a form of disadvantage or harm (e.g. Allport, 1954; Dovidio and Hebl, 2001; Nkomo, 2008), we understand subtle discrimination as everyday interpersonal encounters that are experienced by minority employees as unpleasant, frustrating or upsetting and linked to their ethnic background, but that are relatively 
inconspicuous and often not punishable under anti-discrimination regulations. To better understand how it is experienced in practice, we approach subtle discrimination from the target's perspective. Accordingly, our research questions are: 1) which forms of subtle discrimination do ethnic minority professionals themselves experience in the workplace; and 2) why do they experience these daily events as problematic and discriminatory? Interpreting our findings, we adopt a structural perspective, linking subtle discrimination to power relations and understanding it as micro-level inequalities which are embedded in wider structures, reflecting and sustaining intergroup power inequalities (cf. Essed, 1991).

This study is based on 26 in-depth interviews with second-generation professionals (for example consultants, managers or lawyers) of Turkish or Maghrebi ${ }^{1}$ descent working in majority-dominated workplaces in Flanders, Belgium. It contributes to our thinking about discrimination at the workplace by de-naturalizing specific workplace behavior that might be considered as normal. Furthermore, this study shows how subtle discrimination is intrinsically linked to power differences and the broader societal context as it involves the experience of being constructed as either a hierarchical inferior or an exotic other, and the experience that the ethnic majority is defending their dominant position through the reproduction of specific norms or the maintenance of unequal ethnic structures.

\section{Old problems, alternative approaches}

\section{Blatant vs. Subtle Forms of Discrimination}

Since the sixties, societal norms and legislation seem to have become less tolerant for open forms of racism and discrimination, such as racial segregation or views that specific races are inherently inferior. However, it has been argued that this evolution did not end such phenomena, but rather made racism and discrimination transform into more subtle and covert forms that easily slight under the radar (Deitch et al., 2003; Dipboye and Halverson, 2004; 
Kleinpenning and Hagendoorn, 1993). Studies addressing these 'new' forms of racism have mainly tried to conceptualize its origins and introduced concepts such as modern racism, symbolic racism, aversive racism, racial ambivalence and subtle prejudice. Although there are differences between these concepts (Meertens and Pettigrew, 1997; Pettigrew, 2009), they all somehow refer to sometimes unconscious, negative or ambivalent feelings towards minorities, often based on seemingly rational, non-racial arguments, expressed by individuals who commonly believe in equal rights or do not see themselves as racists (Deitch et al., 2003; Gaertner and Dovidio, 1986; Monteith, 1996; Pettigrew and Meertens, 1995). In a similar line, studies focusing on behavioral components of exclusion have adopted the idea of subtle or everyday discrimination, describing forms that are less visible and often not punishable under anti-discrimination legislation. It entails interpersonal discrimination that is often enacted unconsciously or unintentionally and that is entrenched in common, everyday interactions, taking the shape of harassment, jokes, rudeness, avoidance, and other types of disrespectful treatment (Deitch et al., 2003; Dipboye and Halverson, 2004; Essed, 1991; Rowe, 1990).

Examining research on discrimination in the workplace, most attention has been paid to traditional forms of discrimination and racism (Deitch et al., 2003). To our knowledge, only two studies have explicitly and empirically examined these 'new' forms of racism or discrimination in the workplace. Deitch and colleagues (2003) found that 'black' employees reported more mistreatment on the job than 'white' employees, leading to the conclusion that everyday discrimination exists. They further found that such mistreatment is negatively associated with both well-being and job satisfaction. In an experimental study, Brief and coworkers (2000) found that individuals scoring high on a modern racist scale did not discriminate more than people scoring low, unless they were given a business justification by an authority figure to do so. In this way, they feel legitimized to act in accordance to their 
modern racist feelings. We note that other studies might have described forms of subtle discrimination in the workplace without necessarily using that term. For instance, studies exploring avoidant behavior by majority members, exclusion from networks, denial of mentoring, or forms of harassment and bullying (e.g. Fox and Stallworth, 2005; Ibarra, 1995) may have shown part of the variety of forms subtle discrimination can take.

\section{Individual Explanation vs. Contextual Understanding of Subtle Discrimination}

As a field, studies on workplace discrimination have been heavily inspired by social psychological perspectives (e.g. social identity theory), concentrating on individual cognitive processes (Nkomo, 2008; Proudford and Nkomo, 2006). As a consequence, it has adopted a sort of 'methodological individualism' (Wight, 2003), locating the sources of discrimination and prejudice mainly inside the individual, explaining it as the result of psychological processes. This approach is increasingly being criticized by scholars who stress sources outside the individual and argue that prejudice and discrimination are embedded in a specific historical, political and social context and shaped by historic relations between groups, cultural norms and societal discourses (Konrad, 2003; Prasad et al., 2006; Nkomo, 2008; Proudford and Nkomo, 2006). For example, power and socio-economic differences can encourage or reinforce stereotypes and lead to perceptions that the less powerful group is lazy, backward and untrustworthy (Fiske, 1993; Prasad et al., 2006). By ignoring such influences, and solely focusing on individuals and their cognitive processes, researchers run the risk of covering up these deeper, more structural roots of discrimination, leaving us unable to challenge them (Wight, 2003).

In this study, we aim for a contextualized understanding of subtle discrimination in the workplace, paying attention to the broader setting in which these experiences are embedded. Doing so, we follow Essed's $(1991,2002)$ treatment of everyday racism, referring to 
systematic, recurrent, familiar encounters that are part of the everyday experience of being a minority. She argues that from a macro point-of-view, racism can be understood as "a system of structural inequalities", in which "Whites dominate Blacks" (Essed, 2002: 181). However, such a system has to be (re-)created through social interactions. So, from a micro perspective, specific actions, procedures and cognitions can be considered as racism if they are consistent with the macro structure of inequalities, and contribute to the development and reproduction of this system, independent of their specific intentions.

In line with a contextualized approach, we argue that the forms of discrimination and the intergroup interactions found in studies on African Americans in the United States are not necessarily similar to those in Europe. As Pettigrew (1998) argued, the situation of African Americans "is atypical of the world's intergroup situation on many dimensions" (Pettigrew, 1998: 78). For example, African Americans have endured centuries of slavery and segregation, and continue to face racial barriers, but are generally seen to 'belong' in American society. In Europe, on the other hand, many people still question whether the 'new' minorities actually belong in Europe. This is not only true for recently-arrived immigrants (often coming from countries with different linguistic or religious traditions), but even for people of the second- or third-generation (Ceuppens and Geschiere, 2005; Pettigrew, 1998). So, in this article, exploring the experiences of people of Turkish or Maghrebi descent in the Flemish workplace, we focus on a different group in a different context than most other studies on subtle, everyday discrimination, commonly exploring the experiences of racial minorities and/or U.S. society (Fiske, 1998; Swim et al., 1995; e.g. Brief et al., 2000; Deitch et al., 2003; Essed, 1991; Swim et al., 2003).

The Perspective of the Perpetrator vs. Victim

Another aspect that makes this study different from most studies on workplace discrimination 
is that it starts from the target's perspective. Traditionally, research on discrimination has focused on the individuals who hold prejudiced beliefs, and on why, when and how they discriminate against other people (Dion, 2002; Dion et al., 1978; Swim and Stangor, 1998). However, during the last 20 years, studies increasingly started focusing on the victims rather than the perpetrators of discrimination (Nkomo, 2008; Swim and Stangor, 1998).

This perspective has several strengths. First, by bringing forward the voices of minority individuals, one can shed a new light on specific phenomena or interactions that might seem innocent or common-sense, but that are experienced as discriminatory or problematic by minority members (Dion et al., 1978). In this way, the accounts of these individuals can help us question and de-naturalize the status-quo and expose power differences behind seemingly neutral encounters. Second, listening to the victims validates their experiences and might create a form of empathy for the difficulties they encounter in their daily lives. Third, by listening to people who actually experience these phenomena in their everyday lives, we can get a better insight in the extent to which they take place and in the variety of shapes they can take. In other words, it can help us get a better understanding of the daily struggle minority members have to undertake in a majority-dominated society. Finally, it can give a better insight in the processes that influence whether a person interprets a specific encounter as problematic or not. This is especially important when exploring experiences of new forms of discrimination, as they are often characterized by ambiguity and subtlety (Swim et al., 1998, 2003; Swim and Stangor, 1998).

\section{Method}

We adopted an interpretative, inductive approach that gives voice to those experiencing subtle discrimination, which allows us to extend theory from the perspective of those who live it (cf. Lee, 1999). We relied on interviews to gain a better understanding of the variety of 
forms subtle discrimination can take and the reasons why specific incidents are experienced as discriminatory. Interviews are in this case appropriate because they allow us to be open to new, unexpected phenomena, and offer detailed descriptions of specific incidents, giving us a better insight in the complexity surrounding such encounters (Kvale, 1996).

\section{Societal Context of Flanders, Belgium}

Since the Second World War, Belgium and Flanders, the northern, Dutch-speaking part of Belgium where this study was conducted, have known important migration inflows from countries like Spain, Italy, Turkey and Morocco. Looking at the labour market outcomes of these minorities, it is clear that the Flemish labor market is strongly ethnically stratified, as immigrants, especially of Turkish or Moroccan descent are overrepresented in low-wage jobs and unemployment. This weak socio-economic position has its effects on their children, the second-generation, whose education outcomes are a lot worse than those of majority students. So, only a relatively small portion of them manages to obtain a higher educational degree (OECD, 2008: 43-108; Tielens, 2005; Vertommen and Martens, 2005). Trying to address this worrisome situation, the Flemish Government, trade unions and employers' associations have recently started diversity campaigns to reduce the disadvantage of ethnic minorities (OECD, 2008: 43-108).

On a discursive level, individuals of foreign descent are commonly labeled 'allochthons' (allochtonen), which is derived from Greek and literally means 'from another land'. In contrast, 'autochthons' (autochtonen), which literally means 'from the land itself', is used to refer to the indigenous Flemish population. In practice, the label 'allochthons' is mainly reserved for Muslim labor immigrants and their descendents, regardless of their nationality or place of birth. So, even those who have the Belgian nationality often remain seen as outsiders. This excluding discourse is reinforced by the emergence of fear and distrust 
towards Islam, especially after September 11. Allochthons are often linked to social problems, criminality, abusing the system of social security, increased unemployment, terrorism and extremism. Similarly, their weak socio-economic position is often believed to be caused by their unwillingness to learn Dutch or by 'their' values, which are said to be contrary to 'Western' culture (Bousetta and Jacobs, 2006; Ceuppens, 2006; Ceuppens and Geschiere, 2005; De Raedt, 2004; Kanmaz, 2002).

\section{Sample}

This study is based on in-depth interviews with 26 second-generation professionals of Turkish or Maghrebi descent working in majority-dominated organizations in Flanders. In specific, we interviewed individuals who work in white-collar jobs, and on hierarchical levels that are usually dominated by (ethnic) majority employees. So, we focused on individuals who do not fit the stereotypical image of the low-skilled immigrant. The reason for this profile was the fact that the interviewees' a-typical professional position might make them more vulnerable to forms of subtle discrimination, because their token status and the fact that their work contexts may not tolerate overt discrimination. We further focused on secondgeneration immigrants of Turkish or Maghrebi descent as these ethnic groups are important minority groups in Flanders, and associated with weak socio-economic position and Islam. So, our interviewees have reached a certain professional position, but are part of a group with a low societal status and power position. Based on these criteria, we located 26 individuals (12 women and 14 men) through an internet search, with the help of multicultural organizations, contacts in the business world, and snowball sampling, involving asking interviewees to refer us to other professionals of foreign descent (Gobo, 2004). Table 1 gives an overview of the interviewees. 


\section{INSERT TABLE 1 ABOUT HERE}

\section{Empirical material}

The interviews consisted of an open and semi-structured part. Inspired by the Critical Incident Technique (Flanagan, 1954), we first asked interviewees to reflect on moments that had an important impact on their lives and careers. This open question gave us a broad overview of their life experiences and allowed the interviewees to introduce and elaborate on themes they believed were important. We then continued the interview in a more structured way, and asked questions about the following four topics: (1) whether they feel at home at work; (2) their relationship with their co-workers, supervisors, and external actors (e.g. clients); (3) the way they deal with their ethnic background at work, and (4) their sense of self. Finally, we allowed the interviewees to add final comments or reflections. The length of the interviewees ranged from one to three hours.

\section{Analysis of the Empirical Material}

To identify the variety and processes of subtle discrimination, we followed the logic of grounded theory (Glaser and Strauss, 1967; Locke, 2001). We carefully went through the narratives and isolated interview parts that referred to experiences of subtle discrimination. In contrast to most studies on workplace discrimination, we did not directly ask whether interviewees felt they had been discriminated or not. The reason for this lies in the observation that all (or most) incidents of racism and discrimination are attributionally ambiguous (Deitch et al., 2003; Ruggiero and Taylor, 1997). As it is (almost) never completely clear whether a specific action is based on prejudice or racism, it is commonly up to the target to interpret a specific occurrence as discrimination or not. However, it has been noted that individuals are often reluctant to do so, even if they acknowledge that 
discrimination against their group exists on a general level (Crosby, 1984). The reason for this is that individuals want to maintain a sense of control over their own lives, do not like to see themselves as victims, have a strong desire to uphold their belief in a just world or fear resentment if they complain about discrimination too much. Further, different people understand and interpret the concept differently, for example influenced by previous experiences (Crosby, 1984; Deitch et al., 2003; Dovidio and Hebl, 2001; Fiske, 1998; Gutek et al., 1996; Ruggiero and Taylor, 1997). So, using an approach that only interprets experiences as discrimination if individuals explicitly define them as such might underestimate the phenomenon, only describing instances in which it was absolutely clear to the interviewee that this occurrence was discrimination.

Moreover, most people use the intentions of specific behavior as a criterion to judge whether something is discrimination or racism. This often means that if they call something discrimination, they also feel they have to identify someone else as an offender or a racist, which is something people are often reluctant to do (Crosby, 1984). However, intent might not be the best criterion to judge discrimination on, as behavior can disadvantage or hurt minorities regardless of its motivations (Crosby, 1984; Essed, 1991; 2002). In line with these considerations, and informed by Deitch and colleagues (2003) who used measures of mistreatment or unfair treatment to study everyday discrimination, we identified incidents as subtle discrimination if these encounters made people feel upset, uneasy, frustrated or treated unfairly, and if these were linked (or perceived to be linked) to their descent. Guided by this criterion, the first author compiled 139 incidents of subtle discrimination across all 26 interviews.

We then used a coding system in which codes were derived inductively from interviews and ultimately agreed upon by both authors. To identify the variety of subtle discrimination, the first author first coded the statements in terms of what event was mentioned. Then, he 
looked for the reason why this event was experienced as problematic and coded underlying processes. After having coded the statements from 13 interviews, the second author went through this coding schema and discussed the coding with the first author. This resulted in adaptation of some of the initial codes, and in axial coding for the underlying processes of subtle discrimination, leading to a first attempt of second-order coding constructs. After this discussion, the first author used this new coding scheme to (re)code the initial and remaining interview statements. The results of this coding were again evaluated by the second author leading to further refinement. In a final phase, both authors jointly coded the remaining statements about which disagreement had arisen until final agreement was reached. This coding process makes traditional inter-rater reliability measures impractical, as new codes emerge throughout the process and are not determined a priori. Figure 1 presents the final coding scheme with 16 different forms of subtle discrimination and 4 major reasons of why particular encounters and behaviors were experienced as discriminatory. Table 2 provides illustrations for each coding category.

\section{INSERT FIGURE 1 ABOUT HERE}

\section{INSERT TABLE 2 ABOUT HERE}

\section{Reflections on the material and its analysis}

Before proceeding to our finding, we believe it is important to offer some reflections on the empirical material and our interpretations. Concerning the empirical material, it is first important to note all interviews were conducted by the first author, who is a young male 'autochthon'. It is important to acknowledge that this ethnic (and sometimes gender) difference might have influenced the interview narratives. Second, we also acknowledge that 
by interviewing individuals because of their ethnic background, we ourselves categorized them. Still, we feel this is a necessary evil to gain insight in the experiences of subtle discrimination and to challenge the forms of oppression the interviewees face.

Concerning the analysis, some might object to the fact that we identify specific incidents as discrimination even though they might be well-intended or not be given that name by the interviewees. In this, it has to be acknowledged that research, specific interpretations and language always offer specific ways of looking at the world, rather than representing it innocently or neutrally. This makes every interpretation and representation a political act, either reproducing or challenging the current status-quo (Alvesson and Deetz, 2000; Alvesson and Sköldberg, 2000). As Essed (1991) noted, studying everyday racism (or subtle discrimination) involves a process of de-naturalization, questioning and challenging processes that are taken for granted and perceived as normal in current society. It is only through shedding a new light on what seems neutral (by labeling it discrimination) and exposing the power relations hidden underneath the common-sense, that we can inspire reconsideration, dialogue and a rethinking of reality (Alvesson and Deetz, 2000; Alvesson and Willmott, 2003).

When reading the examples of subtle discrimination, it is important to remember that incidents which might seem unimportant if they are experienced just once, can become troublesome if they take place in a context of enduring structural inequalities. In order to demonstrate that subtle discrimination is ever-returning, we have chosen to illustrate the findings with narratives from only six interviewees. In this way we can give an overview of the experiences of different individuals, and still do justice to the continuous nature of subtle discrimination experienced by a single person (cf. Essed, 1991). Before proceeding, we shortly introduce these 'main characters'. Altan (36) is the youngest son of two Turkish bluecollar workers. After starting his career as labourer, he moved to several jobs in the social 
sector. In the meantime, Altan obtained a degree in accounting and one in social work and social policy. At the time of the interview, he worked as the policy coordinator on family and education issues for a Flemish city. Fayza (37) was born in Belgium, but lived in Morocco between the age of two and five. Her father worked in an automobile factory, while her mother stayed home to take care of 10 children. Fayza obtained a degree of translator/interpreter, but started working at a consulting firm after following a two-year MBA-program. Zafir (35) was born near Antwerp, where his Moroccan father worked in a blue collar job. Zafir holds a degree in commercial science, and worked as a marketing manager at the moment of the interview. Hicham (29) is the son of two labour immigrants from Morocco. He first obtained an engineering degree and then studied physics at the university. However, he worked as a staff member of a political party at the time of the interview. Mehemet (30) is the son of a Moroccan couple that migrated to Belgium in the seventies. After he obtained a law degree, Mehemet started working for the legal department of a local branch of a public institution. At the time of the interview, he worked as a lawyer at a social organization. Mani (30) is one of six children of a Turkish metalworker. She studied applied economics at the university, and worked as a team coordinator at a financial institution at the time of the interview.

\section{Findings}

In this section, we discuss the different forms of subtle discrimination that ethnic minority professionals themselves experienced in the workplace and the reasons of why these particular incidents were experienced as discriminatory. We structure our findings along the four major reasons that we interpreted as crucial to understand subtle discrimination in the workplace. Before doing so, we first want to point to three issues that appear to be inherent to the phenomenon of subtle workplace discrimination. 
First, it became clear that to fully understand the phenomenon of subtle discrimination in the workplace, one cannot ignore the role of experienced discrimination in other areas of life. All interviewees recounted several incidents of discrimination outside work that both they themselves or family and friends experienced. These experiences are important because they can influence the way individuals look at, and experience incidents in the workplace. Second, it has to be noted that events of subtle discrimination are often experienced as very ambiguous. Even if interviewees felt upset by something, they were often uncertain whether discrimination had actually taken place, whether specific behavior was motivated by their descent or whether the majority co-worker actually meant harm by the action. So even though they felt something unjust had happened, the experiences were often difficult for them to grasp. Third, some individuals who had also worked at non-professional levels, noted that this ambiguity seemed to rise with their hierarchical progression. They described the feeling that as they climbed the hierarchical ladder, discrimination did not diminish, but rather became more subtle and ambiguous.

\section{Forms of subtle discrimination reinforcing the lower status of ethnic minorities}

Examining the different incidents that made ethnic minority professionals feel upset or frustrated, we found that a first major reason is that the low societal status of the group to which the minority professionals belonged was reinforced. In some incidents, this happened as our interviewees felt that majority colleagues perceived them as having less competences. A first form which this act of subtle discrimination can take, are incidents in which ethnic minorities felt they were being given excessive support. For example, Hicham told us how he, pursuing a career as a journalist, enrolled in an apprenticeship program of a media corporation targeting individuals of foreign descent. However, he often felt patronized by his co-workers, giving him the feeling that they saw him as someone with less skills: 
I had to work with people who really gave me the feeling of 'we're going to look after you'. While it involved stuff I didn't need that on. What I also noticed very clearly, was that these people had a lot of prejudices, like that my Dutch wasn't that good, that I didn't understand everything that well. While that wasn't true at all. [...] I think, and I hope, that I've adjusted that a bit, and shown that not every allochthon is retarded. So in that sense, I felt it was a bit paternalistic. [...] so very strong guidance, but it was especially the kind of guidance I got. It involved obtuse stuff, about which I thought 'come on!'

A second form of subtle discrimination referring to lack of competence are incidents in which our interviewees experienced that they had to prove themselves more than majority coworkers. For example, Mani had this feeling when she compared herself with others who had started in the organization at the same time as her. She explained it in the following way:

They are not used to working with a Turkish person and in the beginning they're a bit suspicious, like, 'how is this going to turn out?'

A last form of such subtle discrimination are incidents when co-workers insinuated, or seemed to insinuate, they were hired for their job related to diversity because of their descent, rather than their competences.

These three forms of subtle discrimination, all involving ethnic minority professionals' feeling that their co-workers assume they are incompetent, are upsetting because they reinforce ethnic minorities' lower status. Even though our interviewees are highly educated, the societal discourse on allochthons' lack of skills is often infused in everyday interactions, or they themselves, knowledgeable of this discourse, interpret behavior of their co-workers based on it, assuming it is also being applied to them. Such perceptions give minority individuals, or give them the feeling they have, a lower status in the organization because of their descent.

Other types of incidents that were upsetting because they reinforced minorities' lower status, are situations in which their majority colleagues' behaviors or words confirmed, or seemed to confirm, existing biases against their ethnic group. A first form of subtle discrimination causing this feeling are joking and derogatory remarks, reproducing stereotypes about ethnic minorities. For example, Hicham once attended a big editorial staff 
meeting in which African kings were jokingly compared to monkeys. This evoked the following feeling:

Sorry, for me that's really a bridge too far, because I happen to come from Africa, and I don't think this king resembles a monkey. And besides, you can't say 'it's just a joke', sorry, but you know what racism has done in the past, so you can't start claiming it's all neutral and unintentional.

Obviously, such comments were upsetting to him. Similar is the second form which involves negative comments about, or condemnations of, an entire group. For example, Fayza described how a co-worker said the following about Muslims during a dinner:

'I read this book and I know what these Muslims want, they want to conquer the world. And we are all going to be killed, as they think we're all pigs.' That shocked me enormously [...] I said: 'I'm a Muslim, you might not have noticed that, but I happen to be one, and this is unacceptable'.

A third form of this type of subtle discrimination involves specific questions about their descent. Such questions were sometimes experienced as problematic because they seemed to be based on prejudices, linking our interviewees to dominant stereotypes. For instance, Altan told us:

Questions that often return, based on the idea they have of a traditional Turk, who prays five times a day, of whom the wife has a lower status, where the man is the boss, and you know, drives around in a Mercedes, you know. It can't get more cliché than that. So, those kinds of assumptions.

A final, and perhaps surprising, form of subtle discrimination are compliments. They were upsetting for our interviewees as they portrayed them as positive exceptions, indicating their majority co-workers' biases and stereotypes about the rest of their ethnic group. For example, Altan and Hicham told us how they often get compliments about their Dutch being very good, even though they feel it is only average. The compliment for them seems to express the idea that people of foreign descent have bad language skills. Similarly, a majority colleague once said the following to Fayza:

'That's so fantastic about you, Fayza, there ought to be more like you. Why aren't all allochthons examples like you?' And then they think they're giving me a compliment, but 
that's really an insult, you know. An enormous insult, because they're actually admitting they put all the others in the same box. And they don't seem to see that.

So, she felt insulted, as she does not see herself as an 'example' simply because she is funny and pleasant to talk with.

These four forms of subtle discrimination, joking remarks, comments about an entire group, questions and compliments, are experienced as problematic as they reproduce existing discourses about individuals of foreign descent in society, indicating their low societal status. Even though these remarks and comments did not necessarily target the interviewees directly, they were considered problematic, as they confronted them with the fact that the group with whom they identify has, and continues to have, a lower status. Surprisingly, compliments were also sometimes experienced as upsetting by the ethnic minority professionals. Our interviewees commonly resented them as such compliments are a sign to them that even though they individually might no longer be exposed to such specific stereotypes, the prejudices about, and the lower status of, the group with whom they identify, stay intact.

\section{Forms of subtle discrimination treating individuals as the representative of an ethnic group}

A second major reason why ethnic minority professionals experienced particular incidents as discriminatory is that they felt treated as a representative of an (ethnic) group rather than as individuals. In some incidents, this happened when our interviewees felt that their descent overshadowed their competences. This form of subtle discrimination was mainly talked about when interviewees were seen as a suitable candidate for diversity functions. Being asked or appointed to this function, they felt treated as an allochthonous employee, their decent eclipsing their professional competences. The following happened to Mehemet:

I was hired as a legal advisor, and I had been working there for a long time as a legal advisor, but then at a certain moment they started with a process of interculturalization. And me, as an allochthon, yeah, I had to coordinate that process [...] it bothers me a bit that as an allochthon, you always have to work on allochthonous themes [...] I studied law, and I want to do legal work, I don't want to limit myself to one target group. 
In other incidents, our interviewees felt treated as a representative of a strange out-group because their descent seemed to overshadow their broader personal identity and interests. A first form of subtle discrimination that involved this process is being repeatedly asked questions related to their descent. This is frustrating as they felt that their majority co-workers focused too much on their descent, while they themselves would simply like to be treated like other co-workers, and for example discuss 'normal' things, like Belgian politics, television shows or sports. Mani, for example told us:

Just let me be normal, and don't let me draw attention anymore, just let me be normal and do my job. Also, for example when Turkey has been in the news, if something has happened, positive or negative, they come to ask me: 'what do you think about that?' And: 'what are they up to in Turkey?' Like I have to give account of everything that happens in Turkey [...] And sometimes that's, that becomes irritating, like, I can't do anything about that, you know [...] Sometimes it's positive that people ask, but after a while, it becomes too much, a new colleague who again starts asking these same questions. Just leave me do my work, and talk about something else [...] I had a lot of contact with external actors, with suppliers for contract negotiations and yeah, those first contacts were again like 'where is that name from?', so every time that comes back to the fore.

A second form of subtle discrimination that involved this feeling of having their individuality overshadowed by their descent, are incidents in which our interviewees felt that specific behavior was linked to their background rather than to their individuality. A third form is the use of nicknames. For instance, Fayza mentioned how she is sometimes called by a nickname that reduces her to her descent, such as 'the black one'.

All these forms of subtle discrimination were problematic as they made our interviewees feel as representatives of a specific group. Concerning diversity functions, one could argue that it is beneficial to be seen as more capable for a specific job because of their descent. However, minority individuals fear that if they accept such jobs, their competencies will disappear to the background and that they become reduced to an 'allochthonous employee', rather than simply an employee. Such a situation keeps the power differences intact, as 'their' diversity is instrumentally used by people of the dominant group, and as their chances to 
pursue a career in the organization might be reduced, as they get stuck in a racialized pigeonhole function. Repeatedly receiving seemingly neutral questions about their background or religious affiliations is also not always appreciated by our interviewees. On the one hand, this frustration might be caused by the fact that these questions are everreturning. On the other hand, what seems important is that the questions bring one particular type of difference to the fore and reconstruct them as the Other, an 'allochthonous coworker'. As they are often alone with this difference in the workplace, their similarities with other employees are pushed to the background, and they lose their agency over the way they are perceived in the workplace, as it is the dominant group, through asking questions, who decides which differences come to matter. Above all, the difference that is emphasized by the majority is a difference that is stigmatized in Flemish society. In other words, they are not pushed in just any random category; they are being recast into a category of lesser power, a stigmatized position, just like they are in general society.

\section{Forms of subtle discrimination treating differences as problematic}

A third major reason why ethnic minority professionals experienced incidents as discriminatory is that they felt their differences were seen as problematic. In some incidents, this feeling was evoked when they were asked questions about religion which were experienced as judgmental and made them feel they had to legitimize their faith. For example, Mani told us the following about her problems with questions about Ramadan:

They expect justification about why you do that. And sometimes it's hard to explain [...] if you say that fasting is hard, you have to defend for a hundred percent why you participate and explain your faith also for a hundred percent.

Questions about religion were also sometimes experienced as problematic because they seemed to be asked to check whether they could think in a nuanced way about their faith, making our interviewees feel they had to prove they were no religious extremists. For 
example, Altan, then working as the head of an educational institution, sometimes felt tested by his co-workers' questions:

Every now and then, I was tested by certain questions. [...] For example, can a girl with a head scarf be a teacher, yes or no? [...] Yeah, a test like: 'how is he going to respond to this? Is he going to support one way of thinking, or the other, is he going to be nuanced or not?' So those types of tests.

A second, related form of subtle discrimination indicating their differences were seen as problematic involves majority co-workers' reactions to specific cultural and religious practices. In some of these instances, our interviewees felt disapproval. For example, Mani, who did not drink alcohol for religious reasons, once had a supervisor who made it clear to her that he considered this weird behaviour. Similarly, she stopped talking in Turkish during private phone calls, as this once evoked negative reactions from her co-workers.

In other instances, reactions to specific practices were experienced as problematic because they reflected only skin-deep tolerance, rather than true acceptance of their differences. For example, Hicham once tried to explain a specific practice to a co-worker, who saw herself as very open and tolerant, from the point-of-view of a religious Muslim. What followed was this:

It took me about half an hour, and then she nods, and says: 'I still think,...'. Okay, then you see people have their stuck ideas and it's extremely difficult to free them from them. And that was someone who thought of herself that she was really sympathetic towards the multicultural society, that she was open to the theme. But that was completely superficial, completely superficial. Once you started going into it more in-depth, and you really start to analyze something, she got completely jammed.

Common to these different forms of subtle discrimination is that ethnic minority professionals are asked to talk about a particular behaviour that breaks the secular norm which dominates European society and rejects religious expressions in the public sphere (Bousetta and Jacobs, 2006; Triandafyllidou et al., 2006). The questions they received are experienced as discriminatory because they implicitly seem to draw on that norm and point them to their anomaly, making our interviewees feel that have to legitimize their 'deviant' 
behavior. This feeling is obviously only strengthened by the negative societal discourse on Islam, potentially making all questions on Islam menacing. Majority co-workers' expression of disproval of particular practices is only a slight step further, in which the condemnation of 'deviant' behavior is experienced more explicitly. The opposite of condemnation is tolerance, and still it is similar, as it is based on the same Norm against which all behavior is measured, and which makes behavior, even if it is tolerated, abnormal.

\section{Forms of subtle discrimination maintaining the unequal status-quo}

A fourth and last reason of why incidents were upsetting to ethnic minority professionals is that they gave them the feeling that the current status-quo of inequality is maintained. A first form of such subtle discrimination are situations in which nobody intervened when more overt discrimination happened. This was very upsetting to our interviewees as it signaled that majority individuals did not see such occurrence as problematic. One example of this was given by Mehemet, who was extra shocked by discriminatory behavior by a client, when his management showed understanding for it, and tried to accommodate this person.

A second form are situations in which they felt linked to diversity issues for windowdressing. This was upsetting, as they felt treated as an 'Alibi Ali' or 'Excuse Fatima', used by their organization to make them look inclusive whereas in reality the unequal status-quo was maintained. For example, Mehemet told us the following:

You would logically expect that that [head scarf debate] is an item for the work group interculturalization, of which I was the president. But no, it's fixed up at some different platform, without my knowledge. So, then you get the feeling like, we can occupy ourselves with...for example what we did [describes a conscious-raising event] but when it involves real, important issues, the headscarf, then it's fixed up at some separate platform [...] At such a moment, you say to yourself: 'look, it's not really fun to be the local 'Alibi Ali'.

Finally, in some instances, interviewees experienced that their majority co-workers provided insufficient or wrong information. They felt this as a deliberate manipulation to hurt or 
discredit them, which in the long run could hurt their career, and therefore maintain the status-quo. For instance, Zafir was confronted with his co-workers providing him insufficient information:

How do I know that? The person who I succeeded, who did my job for years, and whom I asked for advice every now and then, he said 'they have to give you this, this and this. Normally they always gave that.' But so they were like: 'let's make him muddle on a bit, and curse a bit.'

These last forms of subtle discrimination are problematic as they are experienced as ways to maintain the status-quo of inequality. If minority individuals see that majority members do not react to discriminatory situations, they start questioning the possibility of challenging the status-quo, as it is apparently protected, or condoned by more powerful actors. Similarly, when they are being linked to diversity issues, they often feel (or fear they are) just an 'Alibi Ali', giving the organization the appearance of inclusiveness and care for diversity when this is not the case. In other words, when linked to diversity issues, minority individuals often feel used to protect the dominant position of the majority, or to defend initiatives that might hurt minority members. Finally, manipulation of information also works best when it is based on, and supports, the status-quo and current power structures. Such form of subtle discrimination maintains the status-quo through endangering minorities' ability to perform well and hampering their career progress.

\section{Discussion}

The aim of this paper was to increase our understanding of subtle discrimination in the workplace through exploring its different forms and understanding the underlying processes that make daily experiences problematic and discriminatory. In what follows, we discuss this study's contributions in terms of considering the variety of forms from the target's perspective and understanding the processes of subtle discrimination as tightly linked to power structures in society. We further reflect on the influence of the societal context in 
Europe and its implications to examine discrimination in the workplace.

Forms of subtle discrimination from the target's perspective

Starting from the target's perspective to study the phenomenon of subtle discrimination, our findings highlight a variety of different forms, ranging from forms that are relatively easily understood as discriminatory, to forms that appear at first sight neutral, unproblematic and even well-intended. The most clear-cut discriminatory forms mentioned by the ethnic minority professionals in our study, such as joking and derogatory remarks, negative comments, nicknames, open disapproval of specific practices and the provision of defective information, are also those previously mentioned by studies on everyday discrimination (e.g. Deitch et al., 2003) and racial/ethnic bullying (e.g. Fox and Stallworth, 2005) in the workplace. In addition to these already-known forms, our study also identified forms of subtle discrimination that, to our knowledge, have not been described in previous studies on workplace discrimination. These include the various types of questions, receiving extra support, and receiving compliments. The reason why such forms might have been unacknowledged in empirical research is that they represent perhaps the most subtle forms of discrimination, involving interactions that can easily be perceived as well-intended. However, we argue that it is not the intention that makes specific behavior discrimination. Rather, it is the consequence of specific behavior, and its power effects, that matter, and that turn specific behavior into discrimination. Obviously, such an interpretation makes research from the target's perspective all the more useful.

\section{Underlying processes of subtle discrimination}

This study further suggests that the processes of subtle discrimination are tightly linked to power structures in society. On the whole, it is our interpretation that subtle discrimination 
reproduces the power structures on which it is based, by giving the minority professionals the feeling that, on the one hand, they are outsiders in the organization and, on the other hand, that the majority is maintaining its central position.

The first two categories of subtle discrimination - reinforcement the lower status of ethnic minorities and being treated as the representative of an ethnic out-group - both involve experienced othering (Prasad and Prasad, 2002), or interactions in which they feel approached and constructed in a particular way. This othering reproduces the dominant Flemish diversity discourse, based on the binary of allochthons versus autochthons, between those who naturally belong in Flanders and those who remain the eternal other, and infuses it in workplace interactions. A first form of subtle discrimination are interactions in which they are faced with the reproduction of the societal hierarchy, privileging 'autochthons' over 'allochthons', or of older Orientalistic discourses portraying people of foreign descent as inferior, backward or menacing (Said, 1978). Such status differences and negative expectations might not only influence how they are professionally perceived, but also how they will actually perform themselves (cf. Steele \& Aronson, 1995). However, sometimes they receive compliments that they are not like other people of foreign descent. Such compliments can also be seen as problematic, as they simply seem to get disconnected from other people of foreign descent because they are different from the stereotypical image the majority has of this group. However, this can prevent a broader questioning of these stereotypes (Fiske, 1998) and give the system an aura of meritocracy and tolerance.

However, reflecting Bhabha's (1994) characterization of otherness as ambivalent, and both an "object of desire and derision" (Bhabha, 1994: 67), subtle discrimination can also involve incidents in which they feel perceived as different, but in which this difference is constructed as something interesting, transforming them into exotic strangers, bearers of a mysterious culture. This type of exoticisation of the Other (Caton and Santos, 2009; 
Schwabenland and Tomlinson, 2008), can be seen as a form of subtle discrimination, as it discursively fixes an individual to a specific identity and essentializes his or her difference, making him or her powerless to control their own workplace identity (Bernasconi, 2005; Childs and Williams, 1997; Foucault, 1982). So, in such interactions, the interviewees experience their co-workers want them to be different, as they can gain something from this exotic difference. Moreover, such interactions reproduce the system of binaries, on which the current structures which benefits the majority, rests (Prasad, 2006). So, subtle discrimination can involve both the hierarchization and the exotisation of ascribed differences, which both essentialize these differences and turn the professionals into specific subjects.

The second two categories of subtle discrimination - the experience that their differences are seen as problematic and feeling that the majority maintains the status-quo - both involve the feeling that the majority is defending their own ethnocentric norms and dominance in the work place. The first form of subtle discrimination of this second category works through the power of the Norm, which distinguishes normal from abnormal behavior (Deetz, 2003; Foucault, 1977). In this form of subtle discrimination, the societal ethnocentric Norm, rejecting Islamic and other minority practices, is infused in everyday interactions. This signals to the interviewees that the workplace is still guided by informal monocultural rules (Kersten, 2000), based on the behavior that the majority considers as normal, and that they do not display the correct behavior. In this way, this form of subtle discrimination supports the majority's dominance in the workplace, as it reproduces the norm stating that their behavior is considered normal and that everyone who deviates from this norm either has to assimilate or suffer the exclusionary consequences.

The second form of subtle discrimination pertaining to this category are interactions through which the interviewees are confronted most clearly with the feeling that the majority is trying to maintain the status-quo in the organization. If problematic incidents arise, and 
they are constructed as unproblematic and normal, then the underlying conflicts and power structures become suppressed, leaving them unaddressed and normalized (Alvesson and Deetz, 2005). As a result, this behavior can become part of the 'normal workplace repertoire', reproducing the current structures. In the second form, they feel used themselves to maintain the status-quo, as they feel 'their diversity' is exploited to enrich the dominant center or to serve a symbolic function, legitimizing the current diversity situation in the organization (Cavanaugh, 1997; Kirby and Harter, 2003). Finally, manipulation of information is also works best when it is based on existing power imbalances and existing stereotypes. They can also maintain the status-quo, as they might endanger minorities' ability to be perceived as competent, and hamper their progress. In other words, subtle discrimination can involve interactions confronting minority individuals with the dominant Norm and the maintenance of the current 'ethnic structures'.

\section{Influence of the societal context on subtle discrimination}

Examining subtle discrimination in a European country, this study points to two aspects that research on workplace discrimination has understudied: language and religion. Our findings indicate that language mainly influences subtle discrimination through the idea that people from a different descent, even if they are born in Belgium, do not speak Dutch well. The importance of this linguistic element is linked to the context, as the Dutch language has always been an important aspect in defining the Flemish identity (Blommaert, 1996). This makes it an important marker of identity and a strong potential basis for subtle discrimination in the workplace. Other European research on diversity or discrimination in the workplace has also noted the potential importance of linguistic diversity, and shown how it can be seen by organizations as an added-value (e.g. Janssens and Zanoni, 2005) or hamper work group interaction and result in discrimination (e.g Ogbonna \& Harris, 2006). However, in our study, 
it is not language differences per se that contributed to discrimination. Rather, it is assumed deficit language fluency that plays a role and contributes to ethnic minority professionals' feelings that they are, and remain, second-class individuals.

A second element that appeared to be very crucial to understand subtle discrimination in the Flemish context was religious difference. Here as well, the societal discourse on Islam cannot be ignored. The idea of the Islamic culture as menacing, backward and barbaric has a long history in Western discourse, and has always played an important role in the relational self-definition and constructed superiority of the West (Said, 1978). After the attacks of September 11, this centuries-old discourse has become very salient and strong in Flanders (and the rest of the Western world). In the workplace, this discourse serves as a strong basis for subtle discrimination, and is mainly encountered by the minority professionals when their faith is looked at with suspicion or disdain.

\section{Limitations and Future Research on Discrimination}

One of the limitations of this study is that it focuses heavily on the structural side of the structure-agency combination. Consequently, we risk giving the impression that the interviewees are mere victims of their majority co-workers, and have no agency to engage with the structural constraints or respond to the discrimination they are faced with. In this line, it has to be acknowledged that even without clear outward responses, individuals are actively interpreting a specific act and labeling it as discrimination or not. On the one hand, defining something as discrimination can obviously be a strong weapon to challenge specific behavior, condemn another person, defend a competent sense of self or explain the current career status (Dick and Cassell, 2002). In doing so, they are also discursively constructing boundaries between them and their majority co-workers, who become defined as insensitive or ethnocentric. On the other hand, they can also refuse to reduce themselves to victims of 
discrimination and explain specific incidents away. In this way, these narratives on discrimination could be seen as in a purely discursive tactics to make sense of their work experiences. Even though we acknowledge this possibility, we want to avoid a position reducing everything to language and discourse. Rather, we assume that the narratives have the ability to "convey something beyond itself" (Alvesson and Sköldberg, 2000: 208), but are always embedded in, and influenced by, power structures and earlier experiences with discrimination. Addressing this limitation, future research can benefit from paying more attention to the possibilities of resistance and agency in the context of subtle discrimination.

Besides attending to the interplay of structure and agency, future research could also explore how experiences of subtle discrimination evolve over time. This could be done by approaching the topic through observations or diary studies, rather than retrospectively. Another limitation of this study is that, due to the relative scarcity of the group we studied, we interviewed individuals working in a broad array of organizations and sectors. As a result, the possible influences of the organizational and professional context on subtle discrimination stay underexplored.

As we already indicated above, two aspects that were important in the experiences of subtle discrimination in the Flemish context, religion (Islam) and language, have been relatively underexplored in research on discrimination in the workplace. As this again points to the fact that there are important differences in discrimination against different (ethnic) groups, more research seems needed on a broader variety of (ethnic) minorities in different (national) contexts. Given the very negative discourse on Islam, discrimination against, and the experiences of, Muslim employees might be an important area for future research, not only in Europe, but also in other parts of the (Western) world. Similarly, the influence of language deserves more attention, as it can play a role in the workplace experiences of other immigrant groups throughout the world, such as Hispanic Americans. 


\section{Conclusion}

As the findings of this study strongly indicate, the battle against workplace discrimination is far from over. However, as subtle discrimination is tightly linked to the power structures in society, it is questionable whether organizations can ever be freed of discrimination and prejudices without structural change. What seems important is that, based on the variety of forms of subtle discrimination we identified, the debate on workplace discrimination can be broadened. We believe that it is especially important to understand the processes that make such incidents problematic, as such feelings might also be caused by other behavior or interactions. So, if we want to combat discrimination it might be more important to focus on all types of behavior that might cause the feelings identified here. We also hope that this study contributes to de-naturalizing some assumed unproblematic behavior, and makes majority members more aware of the consequences their behavior can have on minority individuals. In turn, this broader and deeper understanding might inspire people to rethink what they perceive as normal, unproblematic and neutral. 


\section{References}

Allport G (1954) The nature of prejudice. Cambridge : Addison-Wesley Pub. Co.

Alvesson M, Deetz S (2000) Doing Critical Management Research. London: Sage Publications.

Alvesson M, Deetz S (2005) Critical Theory and Postmodernism: Approaches to Organization Studies. In: Grey C, Willmott H (eds) Critical Management Studies: A Reader. Oxford University Press, 60-106

Alvesson M, Sköldberg K (2000) Reflexive Methodology: New Vistas for Qualitative Research. London: Sage Publications.

Alvesson M, Willmott H (2003) Introduction. In: Alvesson M, Willmott H (eds.) Studying Management Critically. London: Sage Publications 1-22

Bernasconi R (2005) "Lévy-Bruhl among the Phenomenologists: Exoticisation and the Logic of 'the Primitive', Social Identities 11(3): 229-45.

Bhabha H (1994) The location of culture London : Routledge

Blommaert J (1996) Language and nationalism: comparing Flanders and Tanzania. Nations and Nationalism, 2(2): 235-256.

Bousetta H, Jacobs D (2006). Multiculturalism, citizenship and Islam in problematic encounters in Belgium. In: Modood T, Triandafyllidou A, and Zapata-Barrero R (eds.) Multiculturalism, Muslims and citizenship, a European approach London: Routledge, 23-36

Brief A, Dietz J, Cohen R, Pugh S, and Vaslow, J (2000) Just doing business: modern racism and obedience to authority as explanations for employment discrimination. Organizational Behavior and Human Decision Processes, 81(1): 72-97.

Caton K, Santos C (2009) Images of the Other: Selling Study Abroad in a Postcolonial World, Journal of Travel Research, 48(2): 191-204. 
Cavanaugh J (1997) (In)corporating the Other? Managing the Politics of Workplace Difference. In: Prasad P, Mills A, Elmes M, and Prasad A (eds.), Managing the Organizational Melting Pot, Dilemmas of Workplace Diversity. Thousand Oaks: Sage, 31-53. Ceuppens B (2006) Allochthons, colonizers, and scroungers: exclusionary populism in Belgium. African Studies Review, 49(2): 147-186.

Ceuppens B, Geschiere P (2005) Autochthony: local or global? New modes in the struggle over citizenship and belonging in Africa and Europe. Annual review of Anthropology, 34: 385-407.

Childs P, Williams P (1997) An Introduction to Post-colonial Theory. London : Prentice Hall Crosby F (1984) The denial of personal discrimination. American Behavioral Scientist, 27(3): 371- 386.

De Raedt T (2004) Muslims in Belgium: A case study of emerging identities. Journal of Muslim Affairs, 24(1): 9-30.

Deetz S (2003) Disciplinary Power, Conflict Suppression and Human Resources Management. In: Alvesson M, Willmott H (eds.) Studying Management Critically. London: Sage Publications, 23-45.

Deitch E, Barsky A, Butz R, Chan S, Brief A, and Bradley J (2003) Subtle yet significant: The existence and impact of everyday racial discrimination in the workplace. Human Relations, 56(11): 1299-1324.

Dick P, Cassell C (2002) Barriers to managing diversity in a UK constabulary: the role of discourse Journal of Management Studies, 39(7), 953-976.

Dion K (2002). The social psychology of perceived prejudice and discrimination. Canadian Psychology, 43(1): 1-10.

Dion K, Earn B, and Yee P (1978) The experience of being a victim of prejudice: an experimental approach. International Journal of Psychology, 13(3): 197-214. 
Dipboye R, Halverson, S (2004). Subtle (and not so subtle) discrimination in organizations. In: Griffith R, O'Leary-Kelly A. (eds) The dark side of organizational behavior. San Francisco: Jossey-Bass, 131-158.

Dovidio J, Hebl, M (2001) Discrimination at the level of the individual: cognitive and affective factors. In: Dipboye R, Colella A (eds.), Discrimination at work: the psychological and organizational bases. New Jersey: Lawrence Erlbaum Associates, 11-35.

El Omari M, Lahlali M (2006) Racisme en Vlaams Belang zijn twee zaken De Standaard, 15 May, p. 41

Essed P (1991) Inzicht in alledaags racisme [original title: Understanding everyday racism]. Utrecht: Het Spectrum

Essed P (2002) Everyday racism: a new approach to the study of racism. In: Essed P, Goldberg D (eds), Race Critical Theories, Oxford: Blackwell Publishers, 176-194

Flanagan J (1954) The critical incident technique. Psychological Bulletin, 51(4): 327-358.

Fiske S (1993) Controlling other people: The impact of power on stereotyping. American psychologist, 48(6): 621-628.

Fiske S (1998) Stereotyping, prejudice and discrimination. In: Gilbert D, Fiske, S and Lindzey G (eds). The handbook of social psychology. New York: McGraw-Hill, 357-411 Foucault M (1977) Discipline and Punish - the birth of the prison London: Penguin Books. Foucault M (1982) The Subject and Power. Critical Inquiry 8 (4): 777-795.

Fox S, Stallworth L (2005) Racial/ethnic bullying exploring links between bullying and racism in the US workplace. Journal of Vocational Behavior 66: 438-456.

Gaertner S, Dovidio J (1986) The aversive form of racism. In: Dovidio J, and Gaertner S (eds.) Prejudice, discrimination and racism. Orlando: Academic Press, 61-89

Glaser B, Strauss A (1967) The discovery of grounded theory: Strategies for qualitative research. Chicago: Aldine. 
Gobo G (2004) Sampling, representativeness and generalizability. In: Seale C, Gobo G, Gubrium J and Silverman D (eds.) Qualitative research practice London: Sage Publications, $435-456$

Gutek, B, Cohen A and Tsui A (1996) Reactions to perceived sex discrimination. Human Relations, 49(6), $791-813$.

Ibarra H (1995) Race, opportunity, and diversity of social circles in managerial networks. Academy of Management Journal, 38(3): 673-703.

Janssens M, \& Zanoni P (2005) Many diversities for many services: Theorizing diversity (management) in service companies. Human Relations, 58: 311-340.

Kanmaz M (2002) The recognition and institutionalization of Islam in Belgium. The Muslim World 92 (1-2): 99-113.

Kersten A (2000) Diversity management. dialogue, dialectics and diversion. Journal of Organizational Change Management 13(3): 235 - 248.

Kirby E, Harter L (2003). Speaking the language of the bottom-line: the metaphor of “managing diversity”. The Journal of British Communication 40(1): 28 - 49.

Kleinpenning G, Hagendoorn L (1993) Forms of racism and the cumulative dimension of ethnic attitudes. Social Psychology Quarterly 56(1): 21-36

Konrad A (2003) Defining the domain of workplace diversity scholarship. Group \& Organization Management 28(1): 4-17.

Kvale S (1996) InterViews, An introduction to qualitative research interviewing. Thousand Oaks: Sage Publications.

Lee T (1999) Using qualitative methods in organizational research. Thousand Oaks, CA: Sage.

Locke K (2001) Grounded theory in management research. Thousand Oaks, CA: Sage. 
Meertens R, Pettigrew T (1997) Is subtle prejudice really prejudice? Public Opinion Quarterly, 61(1): 54-71.

Monteith M (1996) Contemporary forms of prejudice-related conflict: In search of a nutshell. Personality and Social Psychology Bulletin, 22(5): 461-473.

Nkomo S (2008) Discrimination. In: Barling J, Cooper C (eds.) The Sage handbook of organizational behavior, Volume 1: Micro approaches. London: Sage Publications, 657-672.

OECD (2008). Jobs for immigrants. Volume 2, Labour market integration in Belgium, France, The Netherlands and Portugal Paris: OECD Publishing

Ogbonna E, Harris L (2006) The Dynamics of Employee Relationships in a Diverse Workforce: An Ethnic Minority Perspective. Human Relations, 53(3): 379-407

Pettigrew T (1998) Reactions toward the new minorities of Western Europe. Annual review of sociology 24: 77-103.

Pettigrew T (2009) Probing the complexity of intergroup prejudice. International Journal of Psychology, 44(1): 40-42

Pettigrew T, Meertens R (1995) Subtle and blatant prejudice in Western Europe. European Journal of Social Psychology 25: 57-75.

Prasad A (2006) The Jewel in the Crown, Postcolonial Theory and Workplace Diversity. In: Konrad A, Prasad P and Pringle J (eds.), Handbook of workplace diversity. London: Sage, 121-144.

Prasad A, Prasad P (2002) Otherness at large: Identity and difference in the new globalized organizational landscape. In Aaltio I, Mills A (eds.) Gender, Identity and the Culture of Organizations. London: Routledge, 57-71

Prasad P, Pringle J and Konrad A (2006) Examining the contours of workplace diversity: Concepts, contexts and challenges. In: Konrad A, Prasad P, and Pringle J (Eds), Handbook of workplace diversity. London: Sage, 1-22. 
Proudford K, Nkomo S (2006). Race and ethnicity in organizations. In: Konrad A, Prasad P, and Pringle J (Eds), Handbook of workplace diversity. London: Sage, 323-344

Rowe M (1990) Barriers to equality: The power of subtle discrimination to maintain unequal opportunity. Employee Responsibilities and Rights Journal 3(2): 153-163.

Ruggiero K, Taylor D (1997) Why minority group members perceive or do not perceive the discrimination that confronts them: the role of self-esteem and perceived control. Journal of Personality and Social Psychology, 72(2): 373-389.

Said E (1978) Orientalism. London: Penguin books

Schwabenland C, Tomlinson F (2008) Managing diversity or diversifying management? Critical Perspectives on International Business, 4(2/3): 320-333

Steele C, Aronson J (1995) Stereotype threat and the intellectual test performance of African Americans. Journal of personality and social psychology, 69(5): 797-811.

Swim K, Stangor C (1998) Introduction. In: Swim J, Stangor C (eds.) Prejudice, the target's perspective London: Academic Press 1-8

Swim J, Aikin K, Hall W and Hunter B (1995). Sexism and racism: Old-fashioned and modern prejudices. Journal of Personality and Social Psychology, 68(2): 199-214.

Swim J, Cohen L and Hyers L (1998). Experiencing everyday prejudice and discrimination. In: Swim J, Stangor C (Eds.) Prejudice, the target's perspective London: Academic Press 3760

Swim J, Hyers L, Cohen L, Fitzgerald D and Bylsma W (2003) African American college students' experiences with everyday racism: Characteristics of and responses to these incidents. Journal of Black Psychology 29(1): 38-67.

Tielens M (2005) Eens allochtoon, altijd allochtoon? WAV-Rapport.

Triandafyllidou A, Modood $\mathrm{T}$ and Zapata-Barrero R (2006) European challenges to multicultural citizenship: Muslims, secularism and beyond. In: Modood T, Triandafyllidou A 
and Zapata-Barrero R (eds.) Multiculturalism, Muslims and citizenship: A European approach. London: Routledge, 1- 22

Vertommen S, Martens A (2005) Allochtonen beloond: etnostratificatie op de loonmarkt. In: Steunpunt WAV en VIONA. Stuurgroep strategisch arbeidsmarktonderzoek. De arbeidsmarkt in Vlaanderen, Jaarboek, editie 2005. Antwerpen: Garant, 171-186

Wight C (2003) The Agent-Structure Problem and Institutional Racism. Political Studies, 51(4), 706-721 
Table 1 - Overview of interviewees ${ }^{2}$

\begin{tabular}{|c|c|c|c|}
\hline Name & Gender & Background & Job \\
Aahil & M & Moroccan & Pricing Specialist \\
Altan & M & Turkish & Coordinator Education and Family \\
Fayza & F & Moroccan & European Operations Manager \\
Gamze & F & Turkish & Laboratory technician \\
Hasad & M & Turkish & Journalist \\
Hayat & F & Moroccan & Project coordinator \\
Hicham & M & Moroccan & Staff member \\
Jaleel & M & Moroccan & General Manager \\
Jassem & M & Moroccan & Project leader \\
Loubna & F & Moroccan & Vice-manager \\
Mani & F & Turkish & Team coordinator \\
Mehemet & M & Moroccan & Legal advisor \\
Murad & M & Moroccan & Supply Chain Coordinator \\
Noor & F & Algerian & Diversity coordinator \\
Nuray & F & Turkish & Legal advisor \\
Onan & M & Turkish & Management Consultant \\
Osman & M & Moroccan & Personnel \& Organization Manager \\
Rashid & M & Moroccan & City councillor \\
Sabir & M & Moroccan & Account representative \\
Saida & F & Moroccan & Staff member \\
Salime & F & Turkish & Project staff member diversity \\
Saqr & M & Tunisian & Adviser to a Flemish minister \\
Suna & F & Turkish & Adviser to a Flemish minister \\
Umay & F & Turkish & Therapist \\
Vahide & F & Turkish & Pharmacist \\
Zafir & M & Moroccan & Marketing manager \\
\hline
\end{tabular}




\section{Figure 1 - Coding scheme}

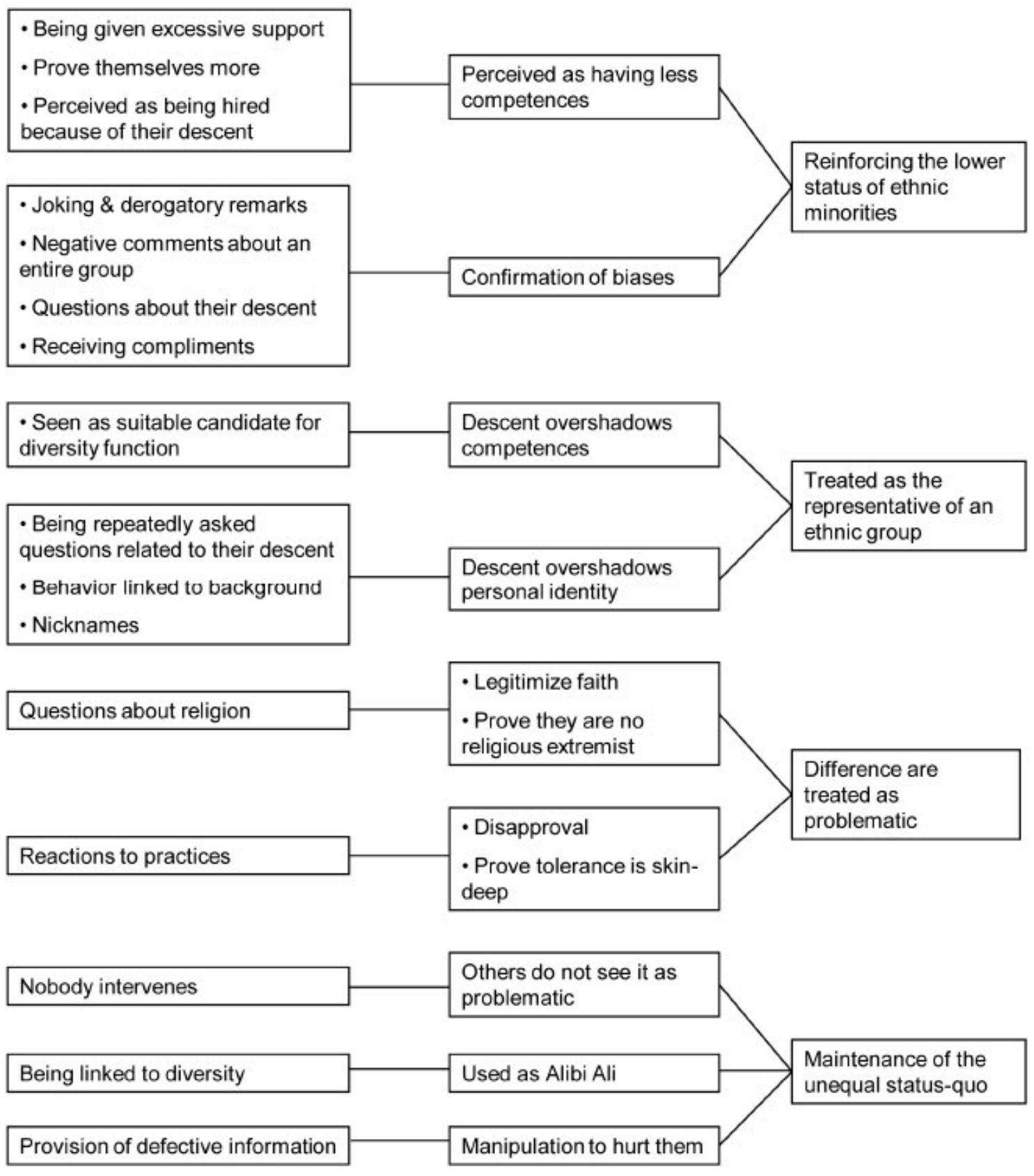




\section{Table 2 - Illustrations for each coding category}

They have the tendency to pamper you, 'we need to support him because he's an allochthon', like 'we have to support him, we have to help him'. They have the tendency to wanting to help you, while I'm like: 'I don't need that, don't look at me as an allochthon, look at me as an employee'.

The reaction was: 'you don't see it, ah, you don't see it. Then you're not a good therapist. That's too bad, what should we do about this? You know, you can stay for a while, we'll give you some more time, we are willing to do that, because in the end, you're Turkish, stay a bit longer.' That was the logic in a way.

In the beginning I really felt I had to prove myself more towards the salespeople, and convince them of my abilities, I think I've been put to the test several times in the beginning [...] you had colleagues who weren't pleased with the fact that I drew up a contract for them, and who really wanted to do it themselves.

Proving yourself more, that has been central in all my work contexts. I've always had to prove myself more than other people. Moreover, I'm also a woman.

I had to give a presentation [...] and suddenly someone says: 'have you seen what they've put on the menu? A cold Turkey! That's probably one of these things we have to do, because we also have to ask one of those, you know, do you think he speaks Dutch?'

You have a lot of people working for you, and a lot of people seemed to think 'it's because it's an allochthon'. I mean, that was a feeling I had in the beginning [...] while they never stopped to think about the things I have to offer

You also heard these joking remarks, like: 'you would have been better off if you worked in the drug sector, then you would have earned more money'.

A joke, $50 \%$ always contains the truth, because you've been able to say it. For example, when they are sending stuff to Africa, or to Latin-America, then they say like 'oh, these guys are probably in their siesta, no need to rush'. Then I think like, if they say that about these guys, then that also applies to me [...] or people who say like 'monkey countries', referring to Africa.

If something happens in the media or something, people come to work and say like: 'did you hear that?' [...] 'Those allochthons, it's again the Moroccans'. I didn't respond to that then, but then they' re criticizing allochthons.

People start debates, it was 2001 back then, 9/11, that situation, they start talking with you about that, and say: 'the Islam has not gone through Enlightenment yet'. And those kinds of debates, you know, peripheral debates, that people start with you, that discourage you, because, they express an ideology, an opinion that doesn't really motivate you.

For example, when people ask me 'are you Muslim?', my trick is always...I say 'can you explain to me how you understand Muslim?', and then it quickly becomes clear, that they see images of planes flying into a tower and like...yeah I try to alter that some way, but you feel that people have really simple ideas about that. And people then for example also think that my parents are going to arrange a marriage for me, for them that's sort of a given.

Sometimes questions [about background] are asked to get confirmation on their way of thinking, then I don't go along in that [...] [questions] to say 'I'm right'. So not with the intention to really listen, but just 'it's like that, come on'.

Being given excessive support

Prove themselves more

Perceived as having less competences

res

Perceived as being hired because of their descent

Joking \& derogatory remarks

Negative comments about an entire group 
Customers often thought I was an intern, or that I was an assistant, then they asked: 'are you an intern?' 'No'. 'You're not a pharmacist, are you?' 'Yes I am'. 'Did you study here?' 'Yes'. 'You're of allochthonous descent?' 'Yes'. 'May I ask of which descent?' ‘Turkish'. 'That's very terrific of your parents, and of you'. That was sort of a feeling like: 'okay'.

Sometimes you take that negatively, I mean, why wouldn't an allochthon be able to study? So that wasn't really positive for me.

So you were confronted with the biggest clichés, like "Islam, all Muslims are terrorists". Really, the biggest clichés. But not you, you're well integrated.

Afterwards I thought, 'is this [recruitment] because I'm of Turkish descent?' I don't want positive discrimination, I have my qualities, I have my education, I have two degrees. I would prefer to be judged based on that, and to be hired based on that, instead of based on things like: 'she speaks Turkish and she's of Turkish origin'.

'Do you want to sit in this selection comity, because we want some more allochthons?' You see? I mean these things are very typical.

I think it's important that people don't talk about it constantly. What I notice, for example, is when you go to receptions, sometimes people you don't know, suddenly start talking about: 'you know, my son has converted to Islam', and 'I have a daughter-in-law and she's also Muslim'. It's like people feel obliged to talk about that topic. While I can just as well talk about other things.

But I was like, debate about that [diversity issues] among yourselves. [...] So every moment you were the representative of something else, you were never yourself, Umay. Or you were never... as the psychologist, simply like, my expertise...my self, that was snowed under, that was pushed too much to the background, other things surfaced, other stuff was constantly mentioned, while my expertise, my knowledge, my being a psychologist was, yeah, a matter of lesser importance. [...] You always have to clarify your position, say you speak for yourself, you have to say you don't represent the entire community.

So the director, of which I thought she was informed, or at least supported the view on diversity, sent me an e-mail and the message was: 'it can't be the idea that we only reach 'excuse Fatima's' and 'Alibi Ali's' with the campaign', and that we had to go broader. While, just a week before, I had written a memo, and had it signed by the minister, and sent to the entire department, with the question to go broader than just ethnic-cultural diverse people. [...] The strange thing is that they keep pinning you down on your identity. While I had formulated that memo more broadly, and had literally said that we also had to reach women, younger people, underprivileged individuals, you know. But suddenly that e-mail was only about allochthons.

Something I'm not so good at, is writing. But that's more linked to the fact that I'm dyslectic than to something else. [...] But she seems to see that as: 'that's someone who hasn't mastered the Dutch language'. [...] I have the feeling she usually sees me as someone who isn't that good at it because I'm of allochthonous descent.

That 'little black one', that's something I hear sometimes, even from my colleagues.

If someone was asking about me, they said 'ah the Turkish one'. [...] You are known as the 'Turkish one'

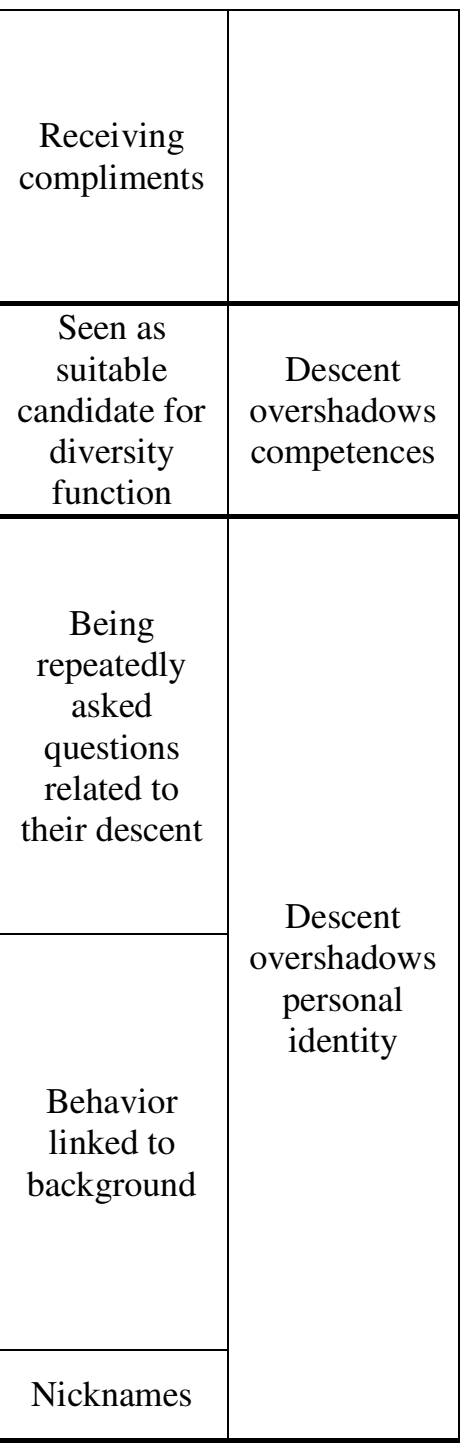


If someone asks me questions about Ramadan, I mean, that's not fun, because it's not really original [...] there is always

that question asking 'why do you do that?' Yeah, because it's my faith, and that's not so easy to understand for someone who doesn't believe, why would you be willing to fast an entire day and come to work?

You can ask a question in a neutral way, if you want to know something about Ramadan, then just ask it. But when you get questions like: 'how can you fast for a God who creates or tolerates suicide bombers?', then where do you have to start? I haven't studied religion you know.

Every now and then I was tested by certain questions, or raising difficult topics. [...] For example: 'can a girl with a head scarf be a teacher, yes or no?' [...] Yeah, a test like, 'how is he going to respond to this?' Is he going to support one way of thinking, or the other, is he going to be nuanced or not. So those types of test.

For example, I was applying for a job at [news organization], and so I got the question, extremely transparent, but still... what was the question again? Oh yes, it was about Darwin, 'yes, you are a Muslim' and a bit later, I got the question, Darwin, 'we see a societal tendency from the U.S. of creationism, what's your view on that?' I felt that question was extremely transparent, they link that to my own...

[interviewer]: So it was more about your position on Darwin?

Right. And about the extent to which you can think critically about Islam.

And then she said 'oh God, I actually think a head scarf is a step backwards'. So she said that to me, without shame, while I had been working for her for three years. So then she really conveys the message like: 'I actually see you as backwards'. We were talking about the headscarf, and I said: 'would I be different if I wore a headscarf?' 'Yes you would.' 'Why?'

$[\ldots]$ They actually admitted they judged people based on how they look, and try to defend that. Then the debate is over for me.

It took me about half an hour, and then she nods, and says 'I still think' ...yes okay, then...but then you see people have their stuck ideas and it's extremely difficult to free them from them. And that was someone who thought of herself that she was really sympathetic towards the multicultural society, that she was open to the theme. But that was completely

superficial, completely superficial. Once you started going into it more in-depth, and you really start to analyze something, she got completely jammed.

The sports department organized a diversity project to get more allochthons and lower-class youth to their sport camps, and they asked me to give my opinion on it. So I provided a lot of ideas, and yeah, I said: 'if you want these kids to come....is there halal food?' They say: 'we have decided we won't do that, we want them to integrate'. I was already glad they didn't say: 'they have to integrate'. [...] So I said: 'then you might as well drop the project'. [...] I mean that's such a simple thing to do. They have to adapt? To what norm?

In the past that would never have happened, that people with a certain position, a certain responsibility, can overtly call someone a monkey: 'do we have to listen to that monkey?' Unheard of, I can't imagine a thing like that was allowed in the past. And nobody reacts, they simply laugh it off like: 'Peter what are you saying?' But openly rejecting it? No

What disappointed me was that supervisor [...] so I had a problem with the fact that...he didn't approve of it, but he

\begin{tabular}{|c|c|}
\hline $\begin{array}{l}\text { Questions } \\
\text { about } \\
\text { religion }\end{array}$ & $\begin{array}{l}\text { Legitimize } \\
\text { faith }\end{array}$ \\
\hline $\begin{array}{l}\text { Questions } \\
\text { about } \\
\text { religion }\end{array}$ & $\begin{array}{l}\text { Prove they } \\
\text { are no } \\
\text { religious } \\
\text { extremist }\end{array}$ \\
\hline $\begin{array}{c}\text { Reactions to } \\
\text { practices }\end{array}$ & Disapproval \\
\hline $\begin{array}{l}\text { Reactions to } \\
\text { practices }\end{array}$ & $\begin{array}{l}\text { Prove } \\
\text { tolerance is } \\
\text { skin-deep }\end{array}$ \\
\hline $\begin{array}{l}\text { Nobody } \\
\text { intervenes }\end{array}$ & $\begin{array}{l}\text { Others do not } \\
\text { see it as } \\
\text { problematic }\end{array}$ \\
\hline
\end{tabular}


refused to call it exclusion or discrimination, he said: 'no, that's exaggerated. I can't approve of it, but...'. That shows me that a lot of employers who might mean well, really don't understand their own way of thinking.

So I clearly told them, during the first conversations we had, for me that was very important, that I wanted to be hired

because I had experience with the topic, diversity. Not because of the fact that I'm of diverse descent. I told them literally,

I said, I don't want to be hired as an Excuse Fatima.

The organization was going to sign a diversity charter [...] they had also sent me an invitation, [...] The moment I walked in there, I thought, 'now I know why they invited me'. The room was full of older men, a few women and one allochthon. So I said to the boss of HR, 'now I know why they invited me' 'yeah, why?' 'I guess I had to bring some color' My supervisor also tried to make me look bad in the eyes of my boss, she said: 'there have been a lot of complaints.' And so I said: 'So far, I didn't get any complaints from clients, can you quote me one example?' And she couldn't, and she was sort of blocked [...] I've noticed that if you're assertive or have certain ambitions, they'll try to curtail them. It's not allowed that a Moroccan can get higher up.

A lot of people, or some people had a problem with the fact that a Moroccan, who happens to have a certain education, enters the organization at a certain pay scale [...] gossip about my work, for example. One example: if I left on holiday, I knew that when I came back, all sorts of things that weren't true would have been spread, but that were seen as truth.

${ }^{1}$ The Maghreb refers to a region in the North-West of Africa. Although it also has narrower (only including some regions) and broader (including Libya and Mauretania) definitions, we understand it here as consisting of Morocco, Tunisia and Algeria.

${ }^{2}$ To protect the anonymity of the interviewees, the names are altered and job titles stay vague.

${ }^{3}$ This is a different Flemish minister than the one Suna works for 